\title{
Sampling for direct search method of all system implementations developed according to the requirements of the technical design specification
}

\author{
K. Sunduchkov prof, Dr., M. Skulysh, PhD, S. Sulima, B. Savchuk \\ Institute of telecommunication systems \\ National Technical University of Ukraine "Igor Sikorsy Kyiv Polytechnic Institute" \\ Kyiv, Ukraine \\ k.sunduchkov@gmail.com, mskulysh@ukr.net, lilthirteen@gmail.com
}

\begin{abstract}
The paper shows that, despite a huge number of generated system variants while designing, possible variants set on which to find the best variant can be reduced by thousands of times without the risk to lose the desired optimal variant. This turned out to be possible because the full set of the generated system variants was obtained without taking into account the constraints that are laid down in the requirements of the technical design specification (TDS). A set of possible system variants is obtained by taking into account the restrictions that are specified in the TDS. Here the word "possible variants" should be understood as reflecting the requirements of TDS. So in the work of the authors [1] 10800 system variants are reduced to 24 systems that meet the requirements of TDS.
\end{abstract}

Keywords—system design; communication networks; multiparametric optimization; new objective function of modified direct search method

\section{INTRODUCTION}

In this paper, as an example, the distribution network of data delivery for mobile subscribers data transmission (whether on the highway or in the railway express) is considered. The parameters of such network more than others approached the requirements of modern and prospective formats for data transmission. Despite the fact that they can be fundamentally different networks, they have several commonalities: for example, a large number of subscribers in the network (hundreds or even thousands of subscribers), high bit rate of signal delivery simultaneously to each (up to $12 \mathrm{Mbps}$ and higher) high network bandwidth, a wide band of operating frequencies.

The analysis showed that further increase in the mobile communication networks data transfer rate is limited by the available bandwidth of the radio channel and the principles of providing communication between subscribers and the base station using traditional handoff procedures.

To ensure an acceptable quality of services, with high mobility of subscribers, various solutions are developed for Wi-Max and LTE technologies to simplify handoff, using"phantom" and "cloud" cells [2, 3, 8], etc.
Work [1] theoretically achieved the data transfer rate of $100 \mathrm{Mbps}$ with a frequency band of $20 \mathrm{MHz}$ with a carrier frequency of $2 \mathrm{GHz}$ and a subscriber's speed of $450 \mathrm{~km} / \mathrm{h}$. To compensate the negative effects due to the carrier frequency reuse and carrier interference due to the Doppler effect, the authors of [8] applied the beamforming algorithm of the antenna pattern.

The most attractive theoretical achievements of a hypothetical mobile network are the following: speed on the highway - $250 \mathrm{~km} / \mathrm{h}$, in the express - $350 \mathrm{~km} / \mathrm{h}$; speed of data transmission to each subscriber - 10-12 Mbps; network capacity (number of subscribers) - up to 2000 mobile terminals.

Further development of the network architecture for the "direct" channel to mobile subscribers on the highway may turn into the "Internet of Things" telecommunications network in the "5G" format.

After 2011, the development of the cluster and cloud computing methods was usually caused by the trend of "green IT" with the growing demand for energy and prices. Computing centers were built more often in cold regions of the Earth. For example, Google's data centers reach PUE (Power Usage Effectiveness) 1.12 due to further optimization of equipment.

It is determined that only $12 \%$ of the energy required for computing was used by servers, and the rest by other services, such as air conditioning, energy distribution, lighting, video surveillance systems, etc. However, according to the Uptime Institute 2012 Data Center Survey, the average PUE has improved.

It is determined that in the area of computation the most efficient for a heterogeneous distribution network is OFDM technology. To eliminate intersymbol interference, a temporary guard interval is entered. Inter-channel interference is attenuated due to the orthogonality of the subcarriers.

From the above review it follows that while synthesizing it is necessary to solve the problem of multiparametric optimization. 
The paper considers the algorithm and procedure proposed by the authors to reduce the set of possible variants of the designed system without the risk of losing the desired optimal variant.

\section{MAIN PART}

\section{A. Modified method of direct search while system synthesizing}

When designing a satellite distribution network for TV programs, we are dealing with a large number of contradictory parameters having both different dimensions and conflicting influences on the objective function of the system in general. In an implementation of the system, in the formation of it, to determine "manually" the optimal version of the system is almost impossible. To solve this problem it is necessary: to develop a technical design specification, to define optimization parameters, to normalize them, to develop mathematical models for calculating optimization parameters, to develop an algorithm for determining the optimal variant of the system, to design an objective function, to set optimization criteria, to choose, or to create a method for solving the optimization problem.

\section{B. General requirements for the network of satellite broadcasting}

- Ensure the broadcasting of programs, the total number of which should be the maximum possible but not less than 400 programs (the number of channels).

- Broadcast quality must meet the following requirements: 4:2:2 transmission quality; Quality reception $\mathrm{BER} \leq 10^{-5}$, where $\mathrm{BER}$ is the probability of a bit error.

- The cost of creating a network should be minimal, while the cost of one transponder should not be more than \$50000 USD (the price determines the transponder class without beam control and routing on it). The cost of the system consisting of: one ES and 10 transponders per SC should not exceed $1063 \cdot 10^{3} \$$ USA.

Based on the technical design specification, lets designate the optimization target parameters as follows:

- $\mathrm{y}_{1}$ - the number of channels in the network;

- $y_{2}-$ the quality of signal reception (estimated by the probability of a bit error of the receiver-decoder) for a given transmission quality (transmission quality = $4: 2: 2)$

- $\mathrm{y}_{3}-$ the cost of the equipment.

\section{The normalization parameters of optimization}

To formulate the problem of multiparametric optimization, it is necessary to perform a normalization of the optimization parameters. For normalization the data of technical requirements can be used.

Since only 3 target parameters are defined in the technical requirements for the satellite broadcasting network: $y_{1}, y_{2}, y_{3}$, it is necessary to determine the primary parameters form which $\mathrm{y}_{1}, \mathrm{y}_{2}, \mathrm{y}_{3}$ depend.

\section{Scheme of the research object}

New developed structural scheme of the aggregative model of the distribution satellite network is presented below (Fig. 1).

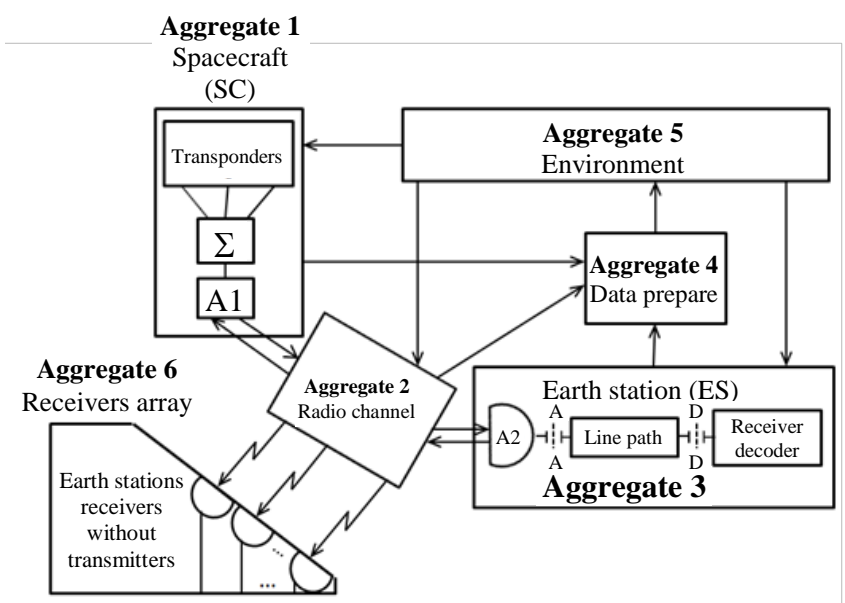

Fig. 1. Structural scheme of the satellite distribution network of TV programs aggregative model

\section{E. Generalized method for solving the synthesis problem}

Additional initial data for solving the synthesis problem based on the structural scheme of the satellite distribution network of TV programs aggregative model:

- The optimal number of transponders on a spacecraft (SC) needs to be determined in the course of solving the problem.

- Each transponder can have a bandwidth of 100 $\mathrm{MHz}$ in the $\mathrm{Ku}$ band $(12 \mathrm{GHz} / 14 \mathrm{GHz})$ or $200 \mathrm{MHz}$ in the Ka band $(18 \mathrm{GHz} / 30 \mathrm{GHz})$.Additional initial data for solving the synthesis of solving the problem.

- $\mathrm{BER}$ - the probability of a bit error of the receiver is equal to one of two values: from $10^{-5}$ to $10^{-6}$. Determine the required $\mathrm{A}=\mathrm{P}_{\mathrm{S}} / \mathrm{P}_{\mathrm{n}}$ and take this into account when calculating variants.

- Consider options for building the system in the $\mathrm{Ku}$ $(12 / 14 \mathrm{GHz})$ and $\mathrm{Ka}(18 / 30 \mathrm{GHz})$ bands at the compression ratio of MPEG-2 and MPEG-4.

- $\mathrm{K}_{\mathrm{MP}}$ - compression ratio using MPEG-2 and MPEG-4 programs (K $\left.\mathrm{K}_{\mathrm{MP}} 2=50, \mathrm{~K}_{\mathrm{MP}} 4=100\right)$.

- $\mathrm{K}_{\mathrm{M}}$ is the FM modulation factor $\left(\mathrm{K}_{\mathrm{M}}=1\right)$, PM2 QPSK $\left(K_{M}=2\right)$, PM3 $\left(K_{M}=3\right)$, PM4 QAM-16 $\left(K_{M}\right.$ $=4)$, QAM-32 $\left(K_{M}=5\right)$, QAM-64 $\left(K_{M}=6\right)$.

The given initial data allows generating 10800 variants of the considered satellite network system.

Based on the generalized method for solving the synthesis problem developed by the authors for systems developed according to the technical design specification [5], for the first time new objective function design for telecommunication systems is proposed: 


$$
\Phi=\prod_{i=3}^{3} R_{i} y_{i}^{n}=R_{1} y_{1}^{n} \cdot R_{2} y_{2}^{n} \cdot R_{3} y_{3}^{n}
$$

where $\mathrm{yi}_{\mathrm{i}}^{\mathrm{n}}$ are the normalized optimization parameters,

$R_{i}$ - Boolean function, that equals to 1 if the parameter value satisfies the technical design specification, or 0 if it does not.

The boolean function was introduced by the authors into the objective function for the principle: "if the parameter is indicated in the technical design specification, then it must be necessarily fulfilled". This principle corresponds to the requirements of experimental design, where the answer to compliance with technical requirements can only be "yes" or "no." The Boolean function introduced this categoricity into the design of the objective function.

The product of the multipliers of the objective function makes it more sensitive to changes. So, for example, the objective function consisting of the additive terms practically does not react to cancelling of any of the terms, since the total sum of them practically does not change.

The analytical expression for the generalized criterion $\mathrm{F}_{\mathrm{ML}}$, called the integral preference criterion (IPC), has the form of

$$
F_{M L}=\min \Phi,
$$

Studies have shown that the objective function $\mathrm{F}$ meets all the requirements and has a high solving power. F allows dividing the entire set of compared systems into two subsets. One of them is a set of systems that do not satisfy at least one requirement of TDS $(\Phi=0)$. The second subset $(0<\Phi \leq 1)$ allows you to rank systems by the degree of satisfaction of the TDS requirements. The integral preference criterion allows not only to take into account all existing forms of TDS requirements, but also to distinguish variants that have large reserves in terms of parameters relative to the requirements in TDS, that ensures greater parametric reliability of the system being developed.

Let's show how it is possible long before the solution of the optimization problem on a huge number of variants of systems, using the requirements of TDS for the optimization target parameters and introducing restrictions on any target parameter, for example, $\mathrm{y}_{1}{ }^{*}$ - the number of satellite radio channels in our example, to reduce by hundreds of times the number of members of the possible variants set (variants satisfying the TDS requirements for the target parameter under consideration).

With the initial data for the two bands $\left(\mathrm{f}_{\mathrm{c} 1}=12 \mathrm{GHz}\right.$ and $\mathrm{f}_{\mathrm{c} 2}=18 \mathrm{GHz}$ ) given in Table 1 , the spectral power density emitted by the transponder in the frequency range $\mathrm{f}_{\mathrm{c} 1}=12 \mathrm{GHz}$ and $\mathrm{f}_{\mathrm{c} 2}=18 \mathrm{GHz}$ depends on the antenna gain $\mathrm{A}^{1}$ I of the signal $\mathrm{f}_{\mathrm{c} 1}$, the diameter of the reflecting mirror of which assumes 5 discrete values from $1 \mathrm{~m}$ to $12 \mathrm{~m}$, and for the signal $\mathrm{f}_{\mathrm{c} 2}=18 \mathrm{GHz}$ the $\mathrm{A}_{\text {II }}^{1}$ antenna with the same diameters of the reflecting 5 mirrors given discretely from $1 \mathrm{~m}$ to $12 \mathrm{~m}$.

Calculation of the required band of operating frequencies for the transmission of one TV program for different input parameters is done using the algorithm shown in Fig. 2. According to the algorithm, the calculation is performed in two frequency ranges $f_{c 1}=12$ $\mathrm{GHz}$ and $\mathrm{f}_{\mathrm{c} 2}=18 \mathrm{GHz}$. At the same time, MPEG2 and MPEG4 compression programs with compression ratios equal to $\mathrm{K}_{\mathrm{MPEG} 2}=50$ and $\mathrm{K}_{\mathrm{MPEG} 4}=100$ are used in both bands.

TABLE I. SPECTRAL POWER DENSITY AND OTHER PARAMETERS OF

\begin{tabular}{|c|c|c|c|c|}
\hline \multicolumn{3}{|c|}{$\begin{array}{c}\text { Signal and transponder } \\
\text { parameters }\end{array}$} & $\begin{array}{c}f_{\mathrm{c} 1}=12 \mathrm{GHz}, \mathrm{P}=20 \mathrm{~W}, \\
\Delta \mathrm{f}_{\mathrm{tr1} 1}=100 \mathrm{MHz}\end{array}$ & $\begin{array}{c}\mathbf{f}_{\mathrm{c} 2}=18 \Gamma \Gamma \mathrm{L}, \mathrm{P}=40 \mathrm{~W}, \\
\Delta \mathrm{f}_{\mathrm{tr} 2}=\mathbf{2 0 0} \mathrm{MHz}\end{array}$ \\
\hline \multicolumn{3}{|c|}{ Parameters $A_{I}^{1}, A_{I I}^{1}$} & $20 w \cdot \kappa_{y}^{A l}$ & $40 W \cdot \kappa_{y}{ }^{A_{H I}^{1}}$ \\
\hline $\begin{array}{l}\varnothing \\
\mathrm{m}\end{array}$ & $\begin{array}{c}\mathrm{K}_{\mathrm{y}}^{\mathrm{Nl}^{1}} \\
\text { [times] }\end{array}$ & $\begin{array}{c}K_{y}^{A_{f t}^{1}} \\
{[\text { times] }}\end{array}$ & & \\
\hline 1 & $9.46 \cdot 10^{3}$ & $2.13 \cdot 10^{4}$ & $18.92 \cdot 10^{-4}[\mathrm{~W} / \mathrm{Hz}]$ & $4.26 \cdot 10^{-3}[\mathrm{~W} / \mathrm{Hz}]$ \\
\hline 2,7 & $6.9 \cdot 10^{4}$ & $1.55 \cdot 10^{5}$ & $138 \cdot 10^{-4}[\mathrm{~W} / \mathrm{Hz}]$ & $31.3 \cdot 10^{-3}[\mathrm{~W} / \mathrm{Hz}]$ \\
\hline 5,0 & $23.5 \cdot 10^{4}$ & $5.32 \cdot 10^{5}$ & $470 \cdot 10^{-4}[\mathrm{~W} / \mathrm{Hz}]$ & $106 \cdot 10^{-3}[\mathrm{~W} / \mathrm{Hz}]$ \\
\hline 7,5 & $52.87 \cdot 10^{4}$ & $12 \cdot 10^{5}$ & $105.7 \cdot 10^{-3}[\mathrm{~W} / \mathrm{Hz}]$ & $241.5 \cdot 10^{-3}[\mathrm{~W} / \mathrm{Hz}]$ \\
\hline 12 & $135.36 \cdot 10^{4}$ & $310 \cdot 10^{5}$ & $27.07 \cdot 10^{-2}[\mathrm{~W} / \mathrm{Hz}]$ & $620 \cdot 10^{-3}[\mathrm{~W} / \mathrm{Hz}]$ \\
\hline
\end{tabular}
TRANSPONDERS

The redundancy factor FEC for all cases is assumed equal to: 5/6, 1/2, 3/4, as shown in Fig. 2. The signal is modulated by different types of modulation from PM1 to QAM64. The modulation factor was assumed to be equal to: from 1 to 6, as shown in Fig. 2.

The required band of operating frequencies in the satellite radio channel can be calculated using the formula below:

$$
\Delta f_{t r}=\frac{\left(13.5 \cdot 10^{6}+6.75 \cdot 10^{6} \cdot 2\right) \cdot 8[\text { Гц }]}{K_{M P E G}(50 ; 100) \cdot F E C(5 / 6 ; 1 / 2 ; 3 / 4) \cdot K_{M}(1 ; 2 ; 3 ; 4 ; 5 ; 6)}
$$

Table 2 shows the calculated bandwidth of the operating frequencies in the satellite radio channel.

Knowing the bandwidth of the operating frequencies, it is possible to calculate how many subcarriers from such a band of operating frequencies can fit in the full bandwidth of the transponder operating frequencies $\mathrm{f}_{\mathrm{c} 1}=12 \mathrm{GHz}$ $\Delta \mathrm{f}_{\text {tr } 1}=100 \mathrm{MHz}$ at $\mathrm{f}_{\mathrm{c} 1}=12 \mathrm{GHz}$ and $\mathrm{f}_{\mathrm{c} 2}=18 \mathrm{GHz} \Delta \mathrm{f}_{\text {tr } 2}=200$ $\mathrm{MHz}$, respectively at a frequency of $18 \mathrm{GHz}$.

It is obvious here that the wider the band of operating frequencies of the subcarriers of the OFDM symbol, the fewer operational signals can be placed on one transponder.

Since an OFDM symbol with a large number of subcarriers is impractical to do, since this leads to large noise in the radio channel, which makes it difficult to fulfill the requirement presented to the ratio $\mathrm{P}_{\mathrm{s}} / \mathrm{P}_{\mathrm{n}}$, we will offer only 2 structures of the OFDM symbol: one of which contains 16 subcarriers, and the other a total of 4 . In this scenario of formation of operating radio channels, other structures are excluded from the consideration.

Due to large noise, OFDM symbols with a large number of subcarriers are excluded. The total number of subcarriers with the bandwidth of one $5,18 \mathrm{GHz} \mathrm{TV}$ program is 19 subcarriers for one transponder of the first $12 \mathrm{GHz}$ band, whereas TDS requires 400 subcarriers that can be placed on only 21 transponders. According to the terms of TDS, only up to 10 transponders are allowed. The proposal clearly does not meet the technical requirements. 


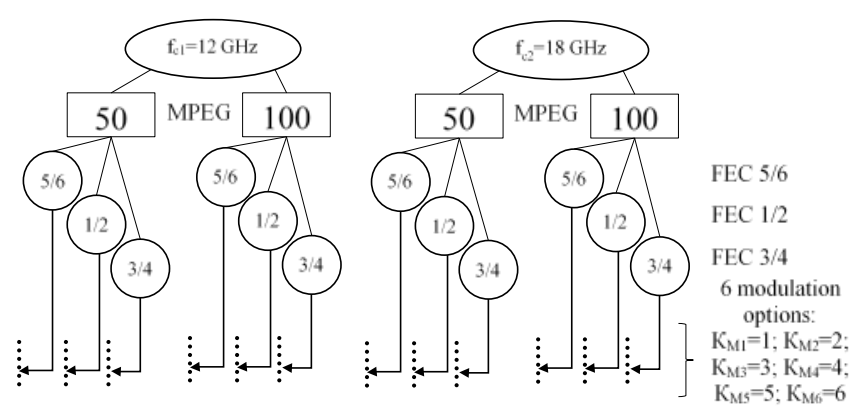

Fig. 2. Algorithm for calculating the required bandwidth for the transmission of a TV program with different input parameters

TABLE II. CALCULATED DATA OF THE REQUIRED BANDWIDTH OF OPERATING FREQUENCIES IN THE SATELLITE RADIO CHANNEL FOR DIFFERENT MODULATION

\begin{tabular}{|c|c|c|c|c|c|c|}
\hline $\mathbf{K}_{\mathbf{M}}$ & $\mathbf{1}$ & $\mathbf{2}$ & $\mathbf{3}$ & $\mathbf{4}$ & $\mathbf{5}$ & $\mathbf{6}$ \\
\hline$\Delta \mathbf{f}_{\mathbf{t v}}^{\mathbf{5 0 ( 5 / 6 )}}[\mathbf{M H z}]$ & 5.18 & 2.59 & 1.73 & 1.295 & 1.036 & 0.86 \\
\hline $\mathbf{\Delta f}_{\mathbf{t v}}{ }^{\mathbf{5 0 ( 1 / 2 )}}[\mathbf{M H z}]$ & 8.64 & 4.32 & 2.88 & 2.16 & 1.73 & 1.64 \\
\hline $\mathbf{\Delta f}_{\mathbf{t v}}{ }^{\mathbf{5 0 ( 3 / 4 )}}[\mathbf{M H z}]$ & 5.76 & 2.88 & 1.92 & 1.44 & 1.152 & 0.96 \\
\hline $\mathbf{\Delta f}_{\mathbf{t v}}{ }^{\mathbf{1 0 ( 5 / 6 )}}[\mathbf{M H z}]$ & 2.59 & 1.29 & 0.86 & 0.647 & 0.52 & 0.43 \\
\hline $\mathbf{\Delta f}_{\mathbf{t v}}{ }^{\mathbf{1 0 0 ( 1 / 2 )}}[\mathbf{M H z}]$ & 4.32 & 2.16 & 1.44 & 1.08 & 0.86 & 0.72 \\
\hline $\mathbf{\Delta f}_{\mathbf{t v}}{ }^{\mathbf{1 0 0 ( 3 / 4 )}}[\mathbf{M H z}]$ & 2.88 & 1.44 & 0.96 & 0.72 & 0.58 & 0.48 \\
\hline
\end{tabular}

To verify compliance with the TDS for the quality index, it is necessary to determine the signal level of the signal transmitted to the Earth station input. Determine the noise power level at the Earth station input. Calculate their ratio:

$$
\mathrm{B}=10 \lg \left(\mathrm{P}_{\mathrm{s}}{ }^{\mathrm{inpES}} / \mathrm{P}_{\mathrm{n}}{ }^{\mathrm{inp}}\right)=10 \lg \mathrm{A}
$$

Then, according to the known ratios $\mathrm{BER}=10^{-5}$ with $B=10 \mathrm{~dB}$, if $K_{M}=2$ is used and at $B=30 d B$, if $K_{M}=6$ is used. Determine the suitability of the proposals under consideration by the criterion of compliance with the requirements of the TDS. The elements of the set that are not in accordance with the requirements of the TDS are excluded from further consideration, as not included in the set of possible variants. According to our estimates, in this way, even before the search for the optimal variant, the number of members of the set of possible variants can be reduced by a factor of thousands.

\section{CONCLUSIONS}

The above optimization parameters allow taking into account the consumer requirements for the construction of a TV programs satellite broadcasting system.

The new design of the objective function makes it possible to reduce significantly the range of permissible values by using the Boolean function.

The objective function takes into account the technical requirements for building a satellite network and reduces to a single value for the construction of a system. Due to this,
TV-program broadcasting systems can be compared with each other and a conclusion which one is preferable can be drawn.

The algorithm for finding the optimal variant of the system involves the development of a technical design specification, the determination of parameters of mathematical models for calculating optimization parameters, the development of an algorithm for determining the optimal variant of the system, the design of the objective function, the specification of the optimization criterion, or the creation of a method for solving the optimization problem.

\section{REFERENCES}

[1] K. Sunduchkov and E. Svetsinskaya, "Mathematical models of calculation parameters of optimization at synthesis of the satellite distribution network of TV programs in Ukraine," 4th International Black Sea Conference on Communications and Networking, June 6-9, Bulgaria, 2016.

[2] H. Benn, "5G Mobile Communications for 2020 and Beyond: Vision and Key Enabling Technologies," Samsung Electronics, October 2014

[3] N. Bubnov, S. Volkov, L. Kobzar and K. Sunduchkov, "The directions of development and implementation problems of telecommunication systems $5 \mathrm{G}$ wireless access neworks, including mobile communications" 2015 Second International ScientificPractical Conference Problems of Infocommunications Science and Technology (PIC S\&T), Kharkiv, Ukraine, 13-15 Oct. 2015, pp.220-223.

[4] Sushko S. I. et al. Satellite modem for small corporate data transmission networks //Microwave and Telecommunication Technology, 2004. CriMico 2004. 2004 14th International Crimean Conference on. - IEEE, 2004. - C. 254-255.

[5] Kazimirenko V. Y., Obukhova Z. K., Sunduchkov K. S. Interactivity creation in satellite broadcasting network //Microwave and Telecommunication Technology, 2001. CriMiCo 2001. 11th International Conference on. - IEEE, 2001. - C. 241-242.

[6] Sunduchkov K. S. et al. Unified satellite communication system of Ukraine //IZVESTIYA VYSSHIKH UCHEBNYKH ZAVEDENII RADIOELEKTRONIKA. - 1999. - T. 42. - №. 11-12. - C. 14-23.

[7] Sunduchkov K. S. et al. Small corporate satellite network for data transmission //Microwave and Telecommunication Technology, 2003. CriMiCo 2003. 13th International Crimean Conference. IEEE, 2003. - C. 303-304.

[8] Ilchenko M. E. et al. Requirements for interactive heterogeneous telecommunication 4G network resource for mobile subscribers //Microwave \& Telecommunication Technology, 2008. CriMiCo 2008. 2008 18th International Crimean Conference. - IEEE, 2008. - C. 235-236.

[9] IIchenko M. E. et al. Native stations of the corporate satellite communications networks //Microwave \& Telecommunication Technology, 2005 15th International Crimean Conference. - IEEE, 2005. - T. 1. - C. 275-278.

[10] Yashchuk O. S., Yashchuk I. I., Sunduchkov K. S. Methods of signal formation and conversion in a hybrid radio over fiber network //Microwave and Telecommunication Technology (CriMiCo), 2013 23rd International Crimean Conference. - IEEE, 2013. - C. 289-290.

[11] Sunduchkov K. S., Makarov A. A., Ilchenko M. E. Space telecommunication technologies at the beginning of the third millennium //Microwave and Telecommunication Technology, 2001. CriMiCo 2001. 11th International Conference on. - IEEE, 2001. - C. 3-11. 